\title{
Physicochemical Properties of Choline Chloride-Based Natural Deep Eutectic Solvents (NaDES) and Their Applicability for Extracting Oil Palm Flavonoids
}

\author{
Mohamad Shazeli Che Zain ${ }^{1}\left(\mathbb{D}\right.$, Jen Xen Yeoh ${ }^{2}$, , Soo Yee Lee ${ }^{1}$ and Khozirah Shaari ${ }^{1,2, *(\mathbb{D})}$ \\ 1 Natural Medicines and Products Research Laboratory (NaturMeds), Institute of Bioscience, \\ Universiti Putra Malaysia, Serdang 43400, Selangor, Malaysia; shazelizain@gmail.com (M.S.C.Z.); \\ daphne.leesooyee@gmail.com (S.Y.L.) \\ 2 Department of Chemistry, Faculty of Science, Universiti Putra Malaysia, Serdang 43400, Selangor, Malaysia; \\ yeohjx@gmail.com \\ * Correspondence: khozirah@upm.edu.my; Tel.: +60-3-8942148
}

check for updates

Citation: Che Zain, M.S.; Yeoh, J.X.; Lee, S.Y.; Shaari, K. Physicochemical Properties of Choline Chloride-Based Natural Deep Eutectic Solvents (NaDES) and Their Applicability for Extracting Oil Palm Flavonoids. Sustainability 2021, 13, 12981. https:// doi.org/10.3390/su132312981

Academic Editor:

André M. Da Costa Lopes

Received: 24 September 2021

Accepted: 9 November 2021

Published: 24 November 2021

Publisher's Note: MDPI stays neutral with regard to jurisdictional claims in published maps and institutional affiliations.

Copyright: (c) 2021 by the authors. Licensee MDPI, Basel, Switzerland. This article is an open access article distributed under the terms and conditions of the Creative Commons Attribution (CC BY) license (https:/ / creativecommons.org/licenses/by/ $4.0 /)$.

\begin{abstract}
Oil palm (Elaeis guineensis Jacq.) leaf (OPL) is abundantly generated from oil palm plantations as biomass that is rich in bioactive metabolites, primarily flavonoids. Six natural deep eutectic solvents (NaDES) were synthesized using a direct heating technique from different combinations of choline chloride with 1,2-propanediol (PD), 1,4-butanediol (BD), glycerol (GLY), glucose (GLU), maltose (MAL) and lactic acid (LA). The synthesized NaDES were subjected to physicochemical and biological evaluations comprising physical appearance, density, water activity, viscosity, polarity, thermal behaviors, spectroscopic analysis, cytotoxicity, radical scavenging activities and solubility tests. Compared to aqueous methanol, the synthesized NaDES, which appeared as a slightly to moderately viscous transparent liquid, showed favorable physicochemical properties as extraction solvents with a low cytotoxicity profile on cultured fibroblast cells. Further, the NaDES obtained from the choline chloride:lactic acid (LA) combination showed high free radical scavenging characteristics. Hydrogen bonding interactions were shown to play a significant role in the formation of the NaDES. Further, ultra-high-performance liquid chromatography ultraviolet/photodiode array (UHPLCUV/PDA) analysis revealed that the NaDES from the choline chloride:glycerol (GLY) combination had comparable efficiencies with aqueous methanol regarding extracting flavonoids (luteolin and apigenin derivatives) from OPLs. The results of the present study suggested that the tailor-made NaDES were not only easy-to-use, stable and safe solvents but also suitable for extracting bioactive phytochemical compounds. The study highlighted their potential as an alternative green technology for applications in oil palm biomass utilization programs.
\end{abstract}

Keywords: oil palm leaf; natural deep eutectic solvents; choline chloride; flavonoid extractability; physicochemical; cytotoxicity; free radical scavenging; UHPLC-UV /PDA

\section{Introduction}

In parallel with the development of sustainable chemistry, natural deep eutectic solvents (NaDES) have recently been receiving tremendous attention from scientists globally in accordance with the efforts on the minimal utilization of conventional organic solvents (COS) in industrial applications [1]. NaDES are not only known to be environmentally friendly but were shown to be less toxic, viable, biodegradable, easy to use and can be produced at low costs [2]. Therefore, it has a huge potential to replace COS, which are presently widely applied for the extraction of bioactive components from plant matrixes for downstream applications in the cosmeceutical, nutraceutical and pharmaceutical industries. NaDES are commonly composed of quaternary salts, such as choline derivatives, acting as a hydrogen bond acceptor (HBA), with sugars, organic acids or alcohols acting as a hydrogen bond donor (HBD). The chemical interactions between the protons of the 
hydroxyl groups of the HBDs with those of the HBA leads to strong hydrogen bonding interactions and other intermolecular forces between the NaDES components [3].

Choline chloride is often combined with an alcohol to extract phenolics and flavonoids from plant materials. For example, choline chloride combined with 1,2-propanediol showed enhanced extractability of oleacein and oleocanthal from virgin olive oil [2] and anthocyanins from flower petals of Catharanthus roseus [4] compared with using COS. Moreover, choline chloride combined with each of 1,4-butanediol, 1,6-hexanediol and glycerol could extract flavonoids, such as apigenin [5], rutin [6], myricetin and amentoflavone [7], quercetin, kaempferol and isorhamnetin glycosides [8]. Not limited to alcohols as HBDs, choline chloride was also combined with organic acids, such as lactic acid [9], and sugars, such as glucose and maltose [10], to extract these compounds. Overall, alcohols, organic acids and sugars are the best candidates of HBDs to be paired with choline chloride to form NaDES that are suitable as extraction media for trapping plant phenolics and flavonoids. Meanwhile, ultrasound-assisted extraction (UAE) combined with NaDES (UAE-NaDES method) has often been applied as a method to extract phenolics and flavonoids more efficiently $[11,12]$. The cavitation bubbles that are generated by ultrasonic waves and the shockwave-induced damage to plant cell walls, which causes the rapid liberation of compounds into the NaDES, significantly improved the extraction yield that was obtained [12]. Although the number of articles reported in the literature on the application of NaDES as a green solvent for extraction and separation of phenolics and flavonoids has increased in the recent decade $[2,6,9,13-16]$, more detailed information, such as on their physical appearance, solubility, density, water activity, polarity, viscosity, thermal behaviors, functional group interactions, radical scavenging activities and cytotoxicity profile, is still required for tailor-made NaDES toward a better understanding and assessment of their potential application as an alternative medium for extracting key components from plant matrices.

Malaysia is the second-largest palm oil (Elaeis guineensis Jacq.) producer in the world after Indonesia, bringing billions worth of revenue into the country. As a result of the massive oil palm cultivation, huge amounts of biomass are continuously generated by the industry, raising various issues, such as waste utilization and sustainable environmental protection. At present, oil palm leaves (OPLs) are still underutilized in comparison with other oil palm biomass, such as empty fruit bunches (EFB), oil palm kernels (OPK), oil palm fronds (OPF) and oil palm trunks (OPT) [17]. Our previous studies revealed the potential of OPLs as a bioresource for bioactive phytochemicals, specifically phenolics and flavonoid glycosides. We further demonstrated that these phytoconstituents exhibited potent antioxidant and wound-healing properties [18-21], apart from possessing antimicrobial [22], antitumor promoting [23] and anti-inflammatory activities [24], as reported by other studies.

Continuing our efforts toward maximizing the efficiency of phytochemical extraction from OPLs, we further explored the application of NaDES to extract the main flavonoids (luteolin and apigenin derivatives) from the agrobiomass. Six choline-chloride-based NaDES were synthesized, where the HBA choline chloride was combined with several HBDs, namely, 1,2-propanediol, 1,4-butanediol, glycerol, glucose, maltose and lactic acid (Figure 1), with appropriate molar ratios and water contents. This was followed by the assessment of their physicochemical properties (physical appearance-color and clarity, density, water activity, viscosity, polarity, thermal behaviors, spectroscopic analysis and solubility), and their cytotoxic and radical scavenging activities. Employing ultra-highperformance liquid chromatography ultraviolet/photodiode array (UHPLC-UV/PDA) analysis, the performance of the synthesized NaDES at extracting OPL flavonoids (luteolin and apigenin derivatives) were assessed based on a comparison with aqueous methanol as the standard solvent. We report the obtained results herein, highlighting the great potential of NaDES as a selective green solvent for strategic applications toward a more sustainable oil palm industry. 


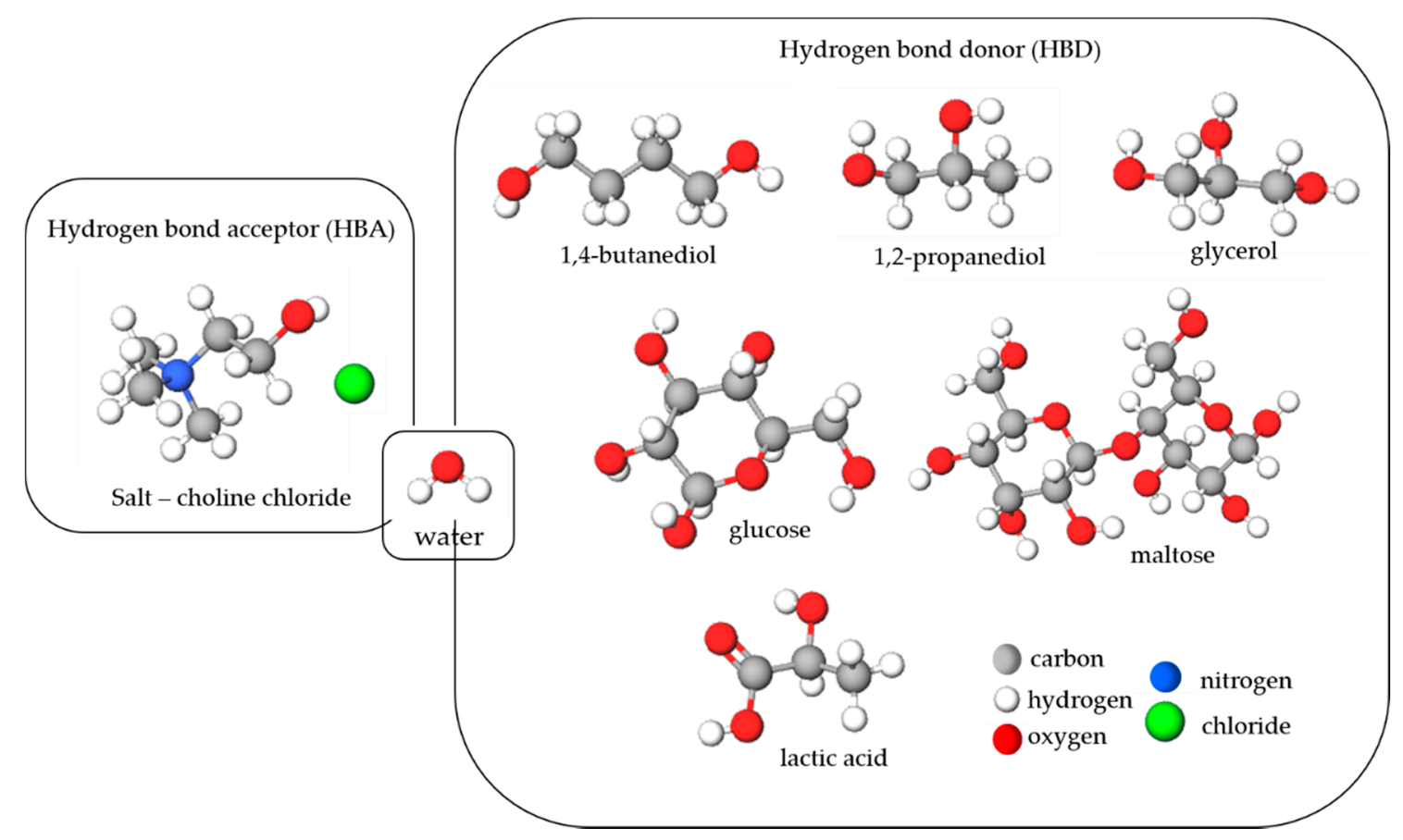

Figure 1. Chemical structures of the hydrogen bond acceptor (quartenary salt), hydrogen bond donors (alcohols, sugars and organic acids) and water as the tertiary components for NaDES synthesis.

\section{Materials and Methods}

\subsection{Materials}

Choline chloride, lactic acid, 1,4-butanediol, 1,2-propanediol, glycerol, glucose, maltose, n-(1-naphthyl) ethylenediamine dihydrochloride, quercetin, sodium acetate, sulphanilamide, 1,1-diphenyl-2-picrylhydrazyl (DPPH) and phosphoric acid were purchased from Sigma-Aldrich (St. Louis, MO, USA). Hydrochloric acid ( $\mathrm{HCl})$, dimethyl sulfoxide (DMSO), sodium hydroxide ( $\mathrm{NaOH})$, formic acid, acetonitrile, HPLC grade acetonitrile and ammonium formate were acquired from Merck (Darmstadt, Germany). Sodium nitroprusside was obtained from Bendosen Laboratory Chemicals (Bendosen, Norway), methanol and ethanol were acquired from R\&R Chemicals (Essex, UK) and aluminum chloride was procured from HmbG Chemicals (Hamburg, Germany). Purified water was obtained using a MilliQ system (Millipore, Bedford, MA, USA). Vitexin, isovitexin, orientin and isoorientin, with higher than $98.0 \%$ purity, were supplied by ChemFaces (Wuhan, China). 3-(4,5-Dimethylthiazol-2-yl)-2,5-diphenyl tetrazolium bromide (MTT) powder was purchased from Solarbio (Beijing, China).

\subsection{Preparation of Oil Palm Leaf Powder}

Mature leaves of Elaeis guineensis Jacq. were harvested from the University Agricultural Park of UPM and assigned the voucher specimen number SK 3332/18. Leaf sample preparation followed the established method that we reported previously [19]. Briefly, the oil palm leaves (OPLs) were cut to an inch in length. The leaflets were freeze-dried at $-50{ }^{\circ} \mathrm{C}$ by using a Labconco ${ }^{\circledR}$ FreeZone Freeze Drier System (Kansas City, MO, USA) until complete moisture removal. To obtain a uniform, small-particle powder, the leaves were ground using a Philips mechanical grinder (HR2056, Eindhoven, The Netherlands) and sieved through a $300 \mu \mathrm{m}$ pore size sieve. The OPL powders were preserved at $-80{ }^{\circ} \mathrm{C}$ prior to use.

\subsection{Synthesis of Natural Deep Eutectic Solvent (NaDES)}

The synthesis of NaDES followed a direct heating method, as described previously [25], with some modifications. Six combinations of NaDES were prepared where choline chloride 
was combined with each of 1,4-butanediol, 1,2-propanediol, glycerol, glucose, maltose and lactic acid, respectively labeled as BD, PD, GLY, GLU, MAL and LA (Table 1). The NaDES components were weighed according to the listed HBA:HBD molar ratios and the mixture was placed in screw-capped glass vials. The mixture was then stirred using a magnetic hotplate stirrer (C-MAG HS7, IKA ${ }^{\circledR}$, Wilmington, NC, USA) set to $800 \mathrm{rpm}$ for $30 \mathrm{~min}$ at $60{ }^{\circ} \mathrm{C}$ with dropwise addition of the required amount of water to help with the solvation. The NaDES that were obtained were stored in screw-capped vials at ambient temperature. The proportion of HBA:HBD molar ratios and water content in the NaDES formulation were pre-optimized based on their performance in extracting flavonoids from OPLs prior to the physicochemical properties being evaluated [26].

Table 1. Various components and molar compositions of NaDES for synthesis.

\begin{tabular}{clccc}
\hline NaDES & \multicolumn{1}{c}{ HBA } & HBD & HBA:HBD Molar Ratio & Water (wt\%) \\
\hline BD & Choline chloride & 1,4-butanediol & $1: 4$ & 33 \\
PD & Choline chloride & 1,2-propanediol & $1: 4$ & 38 \\
GLY & Choline chloride & Glycerol & $1: 3$ & 29 \\
GLU & Choline chloride & Glucose & $1: 4$ & 50 \\
MAL & Choline chloride & Maltose & $1: 3$ & 50 \\
LA & Choline chloride & Lactic acid & $1: 3$ & 17 \\
MeOH & \multicolumn{2}{c}{ Methanol } & & 20
\end{tabular}

The amount of water added into the system was calculated based on the total weight of HBA and HBD. HBAhydrogen bond acceptor; HBD—hydrogen bond donor.

\subsection{Physical Stability, Density, Water Activity, Viscosity, Polarity and Solubility Tests}

The physical appearance and stability of the synthesized NaDES were assessed based on the homogeneity, color, and clarity of the solution. The changes at room temperature that were observed for the color, phase separation, agglomeration, mold formation of NaDES were observed via visual inspection every two weeks over 6 months.

The density $\rho$ was calculated using the formula $\rho=m / v$, where $m$ and $v$ are the mass and volume of the NaDES, respectively. The mass was measured using a calibrated electronic analytical balance (GR-200, A\&D, Tokyo, Japan) with a sensitivity of $0.1 \mathrm{mg}$. A $2 \mathrm{~mL}$ beaker was placed on the scale and tared to zero. Using a calibrated $1 \mathrm{~mL}$ pipette, exactly $1 \mathrm{~mL}$ of NaDES was carefully and slowly transferred to the bottom of the beaker. The mass of the $1 \mathrm{~mL}$ NaDES was recorded and the density was calculated. The measurement was performed in triplicates at room temperature $\left(25 \pm 2{ }^{\circ} \mathrm{C}\right)$.

Water activity was performed using a water activity meter (Legacy Aqualab ${ }^{\circledR}$ Series 3TE, Pullman, WA, USA) at room temperature $\left(25 \pm 2{ }^{\circ} \mathrm{C}\right)$. Briefly, $2 \mathrm{~mL}$ of the sample was poured into a transparent sample cup and the sample cup was sealed and placed in the chamber of the instrument. Viscosity was measured using a sine-wave vibro viscometer (SV-10, A\&D, Tokyo, Japan) operating at room temperature $\left(25 \pm 2{ }^{\circ} \mathrm{C}\right)$. Briefly, $45 \mathrm{~mL}$ NaDES was measured and poured into a transparent sample cup and placed on the instrument platform. The height of the platform was adjusted until the gold sensor plate was at the optimal level. The viscosity tests were performed in triplicates.

The method for testing the polarity was adapted from a previously published paper [27]. Nile red (NR) was used as the solvatochromatic probe to estimate the polarity of the NaDES in the form of molar transition energy $\left(E_{N R}\right)$. The maximum wavelength $\left(\lambda_{\max }\right)$ was measured using a UV-Vis spectrophotometer (UV-1650PC, Shimadzu, Kyoto, Japan). The molar transition energies, $\mathrm{E}_{\mathrm{NR}}$ were calculated using the formula: $\mathrm{E}_{\mathrm{NR}}=\mathrm{hcN} \mathrm{N}_{\mathrm{A}} / \lambda_{\max }$, where $\mathrm{h}$ is Plank's constant $\left(6.626 \times 10^{-34} \mathrm{~m}^{2} \mathrm{~kg} \mathrm{~s}^{-1}\right), \mathrm{c}$ is the speed of light in a vacuum $\left(3 \times 10^{8} \mathrm{~ms}^{-1}\right)$ and $\mathrm{N}_{\mathrm{A}}$ is Avogadro's constant $\left(6.022 \times 10^{23}\right.$ particles $\left.\mathrm{mol}^{-1}\right)$.

Solubility tests were carried out by saturating the NaDES with a $5 \%$ solution of OPL flavonoid-enriched extract, which was obtained from a previous study [19]. The solution was placed in a sample bottle, screwcapped and stirred at $40{ }^{\circ} \mathrm{C}$ for $20 \mathrm{~min}$. The resultant liquid, which contained undissolved solid compounds, was centrifuged and the supernatant was transferred to a $1.5 \mathrm{~mL}$ microcentrifuge tube, diluted with water 
and vortexed until a homogeneous solution was obtained. All the solubility tests were performed in triplicates. A total flavonoid content (TFC) assay analysis was conducted.

\subsection{Thermal Behavioral Studies}

Thermogravimetric analysis (TGA): The thermal stability of the NaDES was investigated using a thermogravimetric analyzer (TGA/SDTA851c, Mettler Toledo, Columbus, $\mathrm{OH}, \mathrm{USA})$. The NaDES with a mass of less than $10 \mathrm{mg}$ were sealed in a $70 \mu \mathrm{L}$ aluminum oxide pan and heated from 50 to $600{ }^{\circ} \mathrm{C}$ with a heating rate of $10^{\circ} \mathrm{C} / \mathrm{min}$ and a nitrogen flow rate of $50 \mathrm{~mL} / \mathrm{min}$. The decomposition temperature $\left(\mathrm{T}_{\mathrm{dcp}}\right)$ was recorded when the maximum weight loss occurred during the TGA runs.

Differential scanning calorimetry (DSC): The glass transition temperature $\left(\mathrm{T}_{\mathrm{g}}\right)$ curve was recorded using a differential scanning calorimeter (DSC 822, Mettler Toledo, Columbus, $\mathrm{OH}, \mathrm{USA})$, ranging from -50 to $50{ }^{\circ} \mathrm{C}$ at a rate of $10^{\circ} \mathrm{C} \mathrm{min}^{-1}$ for the heating and cooling processes. The nitrogen flow rate was set to $50 \mathrm{~mL} / \mathrm{min}$.

\subsection{Spectroscopic Analysis}

Fourier transform infrared (FT-IR) spectroscopy: FT-IR analysis was used to detect the functional groups of a sample. The FT-IR sample technique used was attenuated total reflection (ATR). The ATR was operated by measuring the changes that occurred in an internally reflected IR beam as an interferogram signal, which could then be used to generate an IR spectrum. The spectra were recorded using FT-IR-ATR spectroscopy (IR Tracer-100, Shimadzu, Kyoto, Japan). Transmission spectra were measured in the range of 4000 to $400 \mathrm{~cm}^{-1}$.

Nuclear magnetic resonance (NMR) spectroscopy: Proton and ${ }^{1} \mathrm{H}-{ }^{1} \mathrm{H}$ nuclear Overhauser enhancement spectroscopy (NOESY) experiments were carried out to further understand the proton interaction between the NaDES components. NMR spectra were recorded on a Varian INOVA NMR spectrometer (Varian Inc., Palo Alto, CA, USA) with a frequency of $500 \mathrm{MHz}$. For the spectral measurements, $600 \mu \mathrm{L}$ of the filtered mixture, comprising $300 \mu \mathrm{L}$ of NaDES and $300 \mu \mathrm{L}$ of deuterated methanol, was pipetted into a clean NMR tube. The proton experiment was conducted at $24{ }^{\circ} \mathrm{C}$ and data were acquired with an acquisition time of $3.54 \mathrm{~min}, 2 \mathrm{~s}$ relaxation delay, 64 scans and -2 to $14 \mathrm{ppm}$ spectral width. Further, the ${ }^{1} \mathrm{H}-{ }^{1} \mathrm{H}$ NOESY experiment was performed at $24^{\circ} \mathrm{C}$ and data were acquired with an acquisition time of $135 \mathrm{~min}, 1 \mathrm{~s}$ relaxation delay, 16 scans, -2 to 14 ppm spectral width and 200 ms mixing time. MestRenova (Mestrelab Research, Santiago de Compostella, Spain) was employed for the data processing.

\subsection{Cytotoxicity Assay}

3T3 mouse fibroblasts (Cell Line Service, Appelheim, Germany) were maintained in complete Dulbecco's Modified Eagle Medium (DMEM) high glucose media with 10\% fetal bovine serum (FBS) and 5\% of penicillin-streptomycin in a humidified $5 \% \mathrm{CO}_{2}$ incubator at $37^{\circ} \mathrm{C}$. The medium was changed every $48 \mathrm{~h}$. Cells at $70-80 \%$ confluence were considered to be ready for seeding and treatment throughout the experiment.

The cytotoxicity assay was performed according to a previously published method [18]. Briefly, 3T3 cells were cultured in 96-well microtiter well plates at a density of $1 \times 10^{5}$ cells/well for $24 \mathrm{~h}$. A $100 \mu \mathrm{L}$ aliquot of test samples was added to the well and incubated for $48 \mathrm{~h}$. A total of $20 \mu \mathrm{L}$ of $5 \mathrm{mg} / \mathrm{mL}$ MTT solution was added into each well before the plates were incubated for a further $4 \mathrm{~h}$ at $37^{\circ} \mathrm{C}$. The culture medium was replaced with $100 \mu \mathrm{L}$ DMSO and the absorbance for each well was measured at $570 \mathrm{~nm}$ on a Tecan Infinite F200 Pro plate reader (Tecan Group Ltd., Männedorf, Switzerland). Allantoin was used as a positive control drug, cells without treatment were used as a negative control and wells with only media were used as blanks. Experiments were performed in triplicates. 


\subsection{Determination of Free Radical Scavenging Activity}

1,1-diphenyl-2-picrylhydrazyl (DPPH) free radical scavenging activity: The DPPH free radical scavenging assay followed an established method, as reported earlier [19]. Briefly, $50 \mu \mathrm{L}$ of the test sample or quercetin (positive control) and $100 \mu \mathrm{L}$ DPPH solution were mixed well in a 96-well microtiter plate. The mixtures were incubated for $30 \mathrm{~min}$ and the absorbance was measured at $515 \mathrm{~nm}$ using a Tecan Infinite F200 Pro plate reader (Tecan Group Ltd., Männedorf, Switzerland).

Nitric oxide (NO) free radical scavenging activity: The NO free radical scavenging assay followed a previously published method [19]. Briefly, $60 \mu \mathrm{L}$ of test samples or quercetin (positive control) and $60 \mu \mathrm{L}$ sodium nitroprusside were mixed well in a 96-well microtiter plate. The mixture was incubated at $25^{\circ} \mathrm{C}$ for $150 \mathrm{~min}$. A total of $60 \mu \mathrm{L}$ Griess reagent was added into the mixtures and their absorbance was recorded at $550 \mathrm{~nm}$ using Tecan Infinite F200 Pro plate reader (Tecan Group Ltd., Männedorf, Switzerland).

The calculation for the scavenging activity (SA) was done according to SA $\%=$ $\left[\left(\mathrm{A}_{\mathrm{o}}-\mathrm{A}_{\mathrm{s}}\right) / \mathrm{A}_{\mathrm{o}}\right] \times 100 \%$, where $\mathrm{A}_{\mathrm{o}}$ and $\mathrm{A}_{\mathrm{s}}$ are the absorbance values of the reagent blank and tested samples, respectively. Experiments were performed in triplicates and the results were stated as percentage inhibition (\%).

\subsection{Ultrasound-Assisted NaDES Extraction}

A total of $20 \mathrm{mg}$ of OPL powder was mixed with $2 \mathrm{~mL} \mathrm{NaDES}$ in a $2 \mathrm{~mL}$ microcentrifuge tube and vortexed at $3000 \mathrm{rpm}$ for $30 \mathrm{~s}$. The mixture was then subjected to sonication in an ultrasonic water bath (Branson 2510MT Ultrasonic Cleaner, Darmstadt, Germany) with a frequency set to $40 \mathrm{~Hz}$ at $25^{\circ} \mathrm{C}$ for $30 \mathrm{~min}$. The extraction was performed in triplicates. The mixture was then centrifuged at $4000 \times \mathrm{g}$ rpm over $15 \mathrm{~min}$ to separate the supernatant and precipitate. An aliquot of the NaDES OPL extract was subjected to a TFC assay and UHPLC-UV/PDA analysis.

\subsection{Determination of OPL Flavonoids Contents in NaDES Extracts}

Total flavonoid content (TFC) analysis was performed using a colorimetric assay according to a previously published method [19]. Briefly, $125 \mu \mathrm{L}$ of the NaDES OPL extract was mixed with $375 \mu \mathrm{L} \mathrm{95 \%} \mathrm{ethanol,} 25 \mu \mathrm{L} 10 \%$ aluminum chloride solution, $25 \mu \mathrm{L} 1 \mathrm{M}$ sodium acetate solution and $700 \mu \mathrm{L}$ distilled water in a $2 \mathrm{~mL}$ microcentrifuge tube. The mixture was vortex-mixed and incubated at $25^{\circ} \mathrm{C}$ for $40 \mathrm{~min}$. The absorbance of the mixture was recorded at $415 \mathrm{~nm}$ on a Tecan Infinite F200 Pro plate reader (Tecan Group Ltd., Männedorf, Switzerland). The experiments were performed in triplicates. The results were expressed in milligrams of quercetin equivalents per gram of dried powder (mg QCE/g DP).

Total luteolin (TLC) and total apigenin contents (TAC) were determined using the UHPLC-UV/PDA method [28]. Briefly, a Dionex Ultimate 3000 UHPLC system (Thermo Fisher Scientific, Bremen, Germany) that was fitted with a PDA-3000 photodiode array detector was used to analyze the OPL-NaDES extract solution. An Acquity UPLC ${ }^{\circledR}$ BEH $\mathrm{C}_{18}$ column with a $1.7 \mu \mathrm{m}$ particle size, $100 \mathrm{~mm}$ length and $2.1 \mathrm{~mm}$ internal diameter maintained at $25^{\circ} \mathrm{C}$ was used to separate the samples. The sample elution was performed using a binary mobile phase system set in gradient mode, consisting of aqueous (water and $0.1 \%$ formic acid) and organic phases (acetonitrile and $0.1 \%$ formic acid). The gradient elution proceeded according to the following sequence of organic phase percentages: $10 \%$ for $0-0.6 \mathrm{~min}, 10-13.5 \%$ for $0.6-13.5 \mathrm{~min}, 13.5-100 \%$ for $13.5-15 \mathrm{~min}$ and $100-10 \%$ for $15-16 \mathrm{~min}$. The solvent flow rate and UV detector were set to $0.40 \mathrm{~mL} / \mathrm{min}$ and $340 \mathrm{~nm}$, respectively. For the relative quantification, TLC was calculated using a regression curve that was constructed for orientin $(y=2706.2 \times-19,677)$, while TAC used a calibration curve constructed for vitexin $(y=534.05 \times-6500.5)$, where $x$ represents the metabolite concentration $(\mu \mathrm{g} / \mathrm{mL})$ and y represents the peak area of interest. The values for TLC and TAC were expressed in milligrams of orientin equivalents per gram of dried powder (mg OE/g DP) and milligrams of vitexin equivalents per gram of dried powder (mg VE/g DP), respec- 
tively. The sum of the TLC and TAC gave the total luteolin and apigenin content (TLAC), expressed as milligrams per gram of dried powder (mg/g DP).

\subsection{Statistical Analysis}

Data are expressed as the mean \pm standard deviation (SD) and statistical analyses were performed using Minitab statistical software (Version 16, Minitab Inc, State College, PA, USA) and the InStat V2.02 statistical package (GraphPad Software, San Diego, CA, USA). One-way analysis of variance (ANOVA) completed by Tukey's test was applied to perform analyses to determine significant differences. The significant level was set to $p<0.05$.

\section{Results and Discussion}

\subsection{Physicochemical Characterization of NaDES}

The six synthesized NaDES (PD, BD, GLY, GLU, MAL and LA) were further evaluated physicochemically and compared to those of aqueous methanol $(\mathrm{MeOH})$. The results are shown in Table 2. Different characteristics were observed, depending on the respective compositions of the NaDES. The NaDES varied from being slightly to moderately viscous transparent liquids at ambient temperature, except for MAL and LA, which appeared yellowish, as shown in Figure 2. In terms of physical stability, storage in a desiccator at ambient temperature over six months post synthesis showed that all the synthesized NaDES were stable with no sign of agglomeration, phase separation or mold formation.

Table 2. Physicochemical properties of choline chloride-based NaDES.

\begin{tabular}{|c|c|c|c|c|c|c|c|c|}
\hline Solvent & Liquid Appearance & $\begin{array}{l}\text { Density } \\
\left(\mathrm{g} / \mathrm{cm}^{3}\right)\end{array}$ & $\begin{array}{c}\text { Water } \\
\text { Activity }\end{array}$ & $\begin{array}{c}\text { Polarity } \\
\text { ENR } \\
\text { (kcal/mol) }\end{array}$ & $\begin{array}{l}\text { Viscosity } \\
\text { (cP) }\end{array}$ & $\mathrm{T}_{5}\left({ }^{\circ} \mathrm{C}\right)$ & $\mathrm{T}_{50}\left({ }^{\circ} \mathrm{C}\right)$ & $\begin{array}{l}\text { Solubility } \\
\text { (mg/mL) }\end{array}$ \\
\hline PD & Slightly viscous, transparent & 1.05 & 0.87 & 99.27 & 6.69 & 65 & 134 & $14 \pm 4$ \\
\hline $\mathrm{BD}$ & Slightly viscous, transparent & 1.05 & 0.79 & 100.50 & 9.48 & 79 & 176 & $14 \pm 1$ \\
\hline GLY & Moderately viscous, transparent & 1.18 & 0.67 & 99.45 & 13.1 & 79 & 180 & $15 \pm 6$ \\
\hline GLU & Slightly viscous, transparent & 1.30 & 0.77 & 133.60 & 8.88 & 87 & 216 & $11 \pm 3$ \\
\hline MAL & $\begin{array}{l}\text { Slightly viscous, } \\
\text { yellowish, transparent }\end{array}$ & 1.30 & 0.94 & 113.01 & 7.92 & 70 & 190 & $14 \pm 4$ \\
\hline LA & $\begin{array}{l}\text { Moderately viscous, } \\
\text { yellowish, transparent }\end{array}$ & 1.16 & 0.72 & 93.13 & 12.2 & 76 & 184 & $12 \pm 3$ \\
\hline $\mathrm{MEOH}$ & Transparent & 0.82 & 0.47 & 113.01 & 1.57 & 45 & $97 *$ & $15 \pm 2$ \\
\hline
\end{tabular}

Values are presented as mean \pm standard deviation of three measurements. $\mathrm{T}_{5}$-degradation temperature at $5 \%$ of mass loss in the decomposition stage; $\mathrm{T}_{50}$ or $\mathrm{T}_{\mathrm{dcp}}$-degradation temperature at $50 \%$ of mass loss in the decomposition stage; * evaporation temperature; PD—choline chloride:1,2-propanediol; BD—choline chloride:1,4-butanediol; GLY—choline chloride:glycerol; GLU—choline chloride:glucose; MAL—choline chloride:maltose; LA—choline chloride:lactic acid.

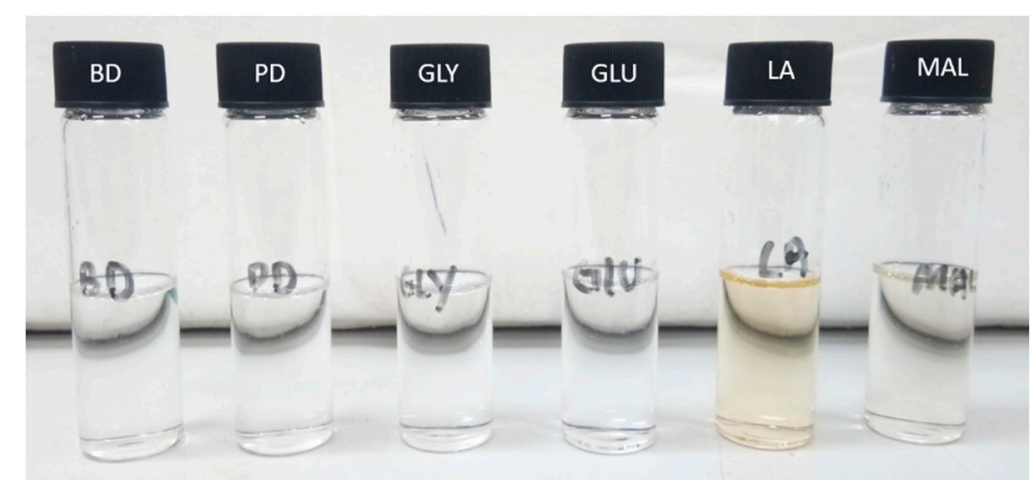

Figure 2. Physical appearance of NaDES. PD—choline chloride:1,2-propanediol; BD—choline chloride:1,4-butanediol; GLY—choline chloride:glycerol; GLU—choline chloride:glucose; MAL—choline chloride:maltose; LA—choline chloride:lactic acid. 
The densities of the six NaDES were determined to be higher than that of $\mathrm{MeOH}$, with values greater than $0.82 \mathrm{~g} / \mathrm{cm}^{3}$. The highest density was found for the sugar-based NaDES (GLU and MAL) with $1.29 \mathrm{~g} / \mathrm{cm}^{3}$, followed by GLY and LA with values of 1.18 and $1.16 \mathrm{~g} / \mathrm{cm}^{3}$, respectively. The alcohol-based NaDES (BD and PD) had the same density value of $1.05 \mathrm{~g} / \mathrm{cm}^{3}$. The results were in agreement with previous findings, which also reported higher density values for NaDES compared to water and methanol [25]. This is attributable to the different degrees of hydrogen bonding in NaDES. The existence of hydrogen bonds leads to highly organized liquids in which the molecules stay connected via strong directional interactions (e.g., hydrogen bonds), with smaller spaces in their structures, resulting in an increased density [27,29].

Water activity is the ratio of the partial pressure of water vapor in a sample to the partial pressure of water vapor in pure water in standard conditions. The water activity values for all six NaDES were higher than the water activity of $\mathrm{MeOH}(0.468)$. The water activity of MAL was the highest with a value of 0.94 , followed by PD, BD, GLU, LA and GLY with values of $0.87,0.79,0.77,0.72$ and 0.67 , respectively. Previous studies reported that high water activity values of more than 0.8 promoted mold growth and reduced shelf-life [30]. Although such drawbacks could be solved by proper storage conditions, for example, using airtight containers at ambient temperature, the water activity value could still be a useful guide for selecting the best extraction solvent for a particular purpose.

Another crucial element in the development of an ideal extraction solvent is viscosity. NaDES are known to have high viscosity and modifications of this characteristic are necessary since it influences mass transfer, solute solubility, dispersion and stability $[6,25]$. The viscosity of the six NaDES decreased with the addition of water, even if only by a small quantity [31]. GLY was the most viscous, followed by LA, with values of 13.1 and $12.2 \mathrm{cP}$, respectively. Among the six NaDES, GLY and LA contained the lowest water contents (29 and 17\%, respectively). On the other hand, the sugar-based NaDES (GLU and MAL) with 50\% water content, and alcohol-based NaDES (BD and PD) with 33-38\% water content were less viscous. These results indicated that the water content that was present in the system greatly influenced the viscosity of the synthesized NaDES, which is consistent with other reports that state that NaDES have a higher viscosity than conventional organic solvents [27,32].

Polarity is very sensitive to a change in water content due to the disruption of hydrogen bondings, inducing a change in the polarity index [14,25,33]. Thus, polarity is an essential aspect of NaDES and is highly related to their solubilizing ability. In this study, LA had the highest polarity, as reflected by the lowest $E_{N R}$ value of $93.13 \mathrm{kcal} \mathrm{mol}^{-1}$. This conformed to the hypothesis that organic-acid-based NaDES are the most polar [25]. The second most polar NaDES were the alcohol-based NaDES (PD, GLY and BD) with polarity values of $99.27,99.45$ and $100.50 \mathrm{kcal} \mathrm{mol}^{-1}$, respectively. These three NaDES showed similar polarities due to the presence of the same functional group $(-\mathrm{OH})$ in their structures. With high polarity values, this explained the high efficiency of these NaDES in extracting polar compounds, such as the targeted OPL flavonoids. Meanwhile, the sugar-based NaDES were the least polar, with a value of $133.60 \mathrm{kcal} \mathrm{mol}^{-1}$ for GLU, and $113.01 \mathrm{kcal} \mathrm{mol}^{-1}$ for MAL, which was very close to the polarity of $\mathrm{MeOH}$, contributing to their huge structures with long carbon chains. This is in agreement with previous studies, which also reported that sugar-based NaDES showed low polarity values [25].

The solubility of the chemical constituents present in a plant matrix is dependent upon the binding power of the solute to the extraction solvent [34]. The solubilizing capacities of the synthesized NaDES were assessed by measuring the amount of TFC obtained after mixing a 5\% solution of OPL flavonoid-enriched extract, which was obtained from our previous study, with the respective NaDES [19]. The results indicated that GLY, PD and BD had the highest solubilizing capability among the six NaDES. It was suggested that the variation in the solubilizing ability could be related to two fundamental reasons, that is, spatial arrangement and binding ability [34]. The NaDES synthesized from different combinations and proportions of HBA, HBD and water components greatly differ in their 
inner supermolecular structures in terms of size, shape and arrangement [34]. Additionally, the strength and stability of hydrogen bondings and other intermolecular forces between the flavonoids and NaDES significantly depend on having the best combination of the components in terms of their carbon chain length and the number of functional hydroxyl and carbonyl groups [13,34]. Thus, these reasons could be the explanation for the high efficiency of the alcohol-based NaDES (GLY, PD and BD) at extracting OPL flavonoids compared to the sugar- (MAL, GLU) and organic-acid-based (LA) NaDES.

\subsection{Thermal Stability}

Thermal stability is another key factor to be considered when designing an extraction medium [3]. The thermal properties of the six NaDES were evaluated via thermogravimetric analysis (TGA) and differential scanning calorimetry (DSC). In general, it was observed that when $5 \%$ mass loss was achieved at temperatures lower than $100{ }^{\circ} \mathrm{C}$, the TGA thermograms displayed mass losses that were largely attributed to loss of the water component of the NaDES (Figure S1). Similar observations were also reported by other researchers [25]. The analysis also revealed that the optimal working temperatures of the NaDES were within the range of 216 to $134^{\circ} \mathrm{C}$, where GLU and PD showed the highest and lowest decomposition temperatures $\left(\mathrm{T}_{\mathrm{dcp}}\right)$, respectively. The TGA thermogram of GLU showed $60 \%$ mass loss between 216 to $470{ }^{\circ} \mathrm{C}$, while PD revealed a 57\% mass loss between 134 to $200{ }^{\circ} \mathrm{C}$, which were proposed to be due to the decomposition of their respective NaDES components. TGA thermograms for BD, GLY, LA and MAL showed slight variations in their thermal decomposition, with $\mathrm{T}_{\mathrm{dcp}}$ at $176,180,184$ and $190{ }^{\circ} \mathrm{C}$, respectively. These findings were similar to previous studies conducted on other synthesized NaDES [3,13]. Various factors could be correlated to the TGA properties, including different HBD and HBA components, the proportion of these components, the water content and method of synthesis, all of which collectively could influence the interaction and formation of intermolecular and intramolecular bonds within the supermolecular complex system, hence contributing to the thermal stability of the solvent [3].

The DSC thermograms provided an insight into the glass transition $\left(\mathrm{T}_{\mathrm{g}}\right)$, crystallization $\left(\mathrm{T}_{\mathrm{c}}\right)$ and melting point $\left(\mathrm{T}_{\mathrm{m}}\right)$ temperatures of the NaDES (Figure S2). Evaluation of the DSC thermograms revealed that the $\mathrm{NaDES}$ and $\mathrm{MeOH}$ glass transition temperatures $\mathrm{T}_{\mathrm{g}}$ were below $-50{ }^{\circ} \mathrm{C}$, which indicated that the complex supermolecular structures of the solvents were able to withstand the critical temperature [13]. Moreover, the DSC thermograms of MAL, GLU and MeOH showed the appearance of an endothermic peak $\left(\mathrm{T}_{\mathrm{c}}\right)$ at $-9,-16$ and $-14{ }^{\circ} \mathrm{C}$, respectively, while the DSC thermogram of MAL showed an exothermic peak $\left(\mathrm{T}_{\mathrm{m}}\right)$ at $-40{ }^{\circ} \mathrm{C}$. The endothermic peak appeared due to the absorption of heat in the NaDES systems, resulting in crystallization of the solvent, while the exothermic peak was due to the release of heat into the system, causing melting of the NaDES. The DSC thermograms of the remaining NaDES did not display any crystallization and melting points. Thus, the thermal stabilities of the NaDES, as observed from the TGA and DSC analyses, indicated that the NaDES are suitable solvents for extracting OPL flavonoids in the temperature range of 0 to $50{ }^{\circ} \mathrm{C}$, which is usually employed in industrial applications [13].

\subsection{Structural and Hydrogen Bonding Interactions between NaDES Components}

The intermolecular interactions of the six NaDES were elucidated using FT-IR and NMR spectroscopies. To begin with, the displacement of functional groups of the individual components and their eutectic mixtures were compared based on the FT-IR spectra shown in Figure 3 and Figure S3. In general, choline chloride, the pure HBA, showed a unique, intense band at $1483 \mathrm{~cm}^{-1}$ that was attributable to $\mathrm{C}-\mathrm{H}$ bending and deformation vibrations of the methyl groups of the trimethyl ammonium $\left(\mathrm{CH}_{3}\right)_{3} \mathrm{~N}^{+}$ion, while an equally intense band observed at $988 \mathrm{~cm}^{-1}$ was due to the quaternary ammonium group or C-N stretching vibrations $[35,36]$. The consistent appearance of weak-to-moderate bands in the region 2868 to $3011 \mathrm{~cm}^{-1}$ in all the NaDES IR spectra were attributable to the $\mathrm{sp}^{3} \mathrm{C}-\mathrm{H}$ stretching vibrations, indicating preservation of the carbon chains of the HBD components in the 
eutectic mixtures. The strong band observed at $1651 \mathrm{~cm}^{-1}$ in all the NaDES IR spectra was due to $\mathrm{H}-\mathrm{O}-\mathrm{H}$ scissoring vibrations that resulted from the addition of water molecules into the system. Meanwhile, the bands observed between 1000 to $1300 \mathrm{~cm}^{-1}$ in the fingerprint region of all the NaDES IR spectra were attributable to C-O, C-C-O and C-O-C stretching and C-O-H bending vibrations. For GLY, the band at $1038 \mathrm{~cm}^{-1}$ may be attributable to the $\mathrm{C}-\mathrm{O}$ linkage between $\mathrm{C}_{1}$ and $\mathrm{C}_{3}$ of glycerol, while the band at $1110 \mathrm{~cm}^{-1}$ could be due to the $\mathrm{C}_{2} \mathrm{C}-\mathrm{O}$ stretching vibration [37]. The $\mathrm{O}-\mathrm{H}$ stretching vibrations are displayed as an intense absorption band at $3350 \mathrm{~cm}^{-1}$ in the FT-IR spectrum of each HBD, which corresponded to the hydroxyl groups in their structures. Interestingly, these bands were relatively stronger and broader in the respective NaDES IR spectra. The band broadening provided more evidence of the enhancement of hydrogen bonding interactions between the components of the eutectic mixture, as previously reported $[27,29,36]$. In addition, as shown in Figure 4, the NOESY spectrum of BD revealed cross-peaks between the hydroxyl proton of either choline chloride or 1,4-butanediol with a water molecule in the system (5.3/4.7 ppm), suggesting the formation of hydrogen bonds between them. A similar interaction was observed in other combinations (Figure S4) and similar findings were reported previously $[25,38,39]$. Thus, this suggested that the involvement of water in the supramolecular structure of NaDES could become a driving force for achieving high performance when extracting flavonoids from OPL.

\subsection{Determination of Cytotoxicity and Radical Scavenging Activities of NaDES}

Although many studies have reported the low or no toxicity of NaDES [40-43], the toxicity data of NaDES that was derived from various primary metabolites were still limited and inadequate as factors such as various combinations and molar ratios of the hydrogen bond donor (HBD) and hydrogen bond acceptor (HBA), as well as water content added, may contribute to different toxicological profiles of the synthesized NaDES. Hence, tailor-made NaDES should be analyzed for their cytotoxicity profiles prior to use as extraction media.

The cytotoxicity of the six NaDES was evaluated against a 3T3 mouse fibroblast cell line and their dose-response curves are shown in Figure 5A,B. Upon exposure, a dose-dependent trend was observed in all NaDES, where cell viability increased as the concentration of the NaDES was decreased. Except for MAL and LA, all NaDES were non-cytotoxic up to $100 \mathrm{mM}$ concentration. GLY, BD, PD and GLU exhibited a very low cytotoxicity profile, with $\mathrm{IC}_{50}$ values ranging from 136.47 to $374.01 \mathrm{mM}$. The high viability of cells when exposed to these HBDs, especially glucose and glycerol, suggested that these are important metabolites that are required by the cells for various cellular activities, such as their role in energy production through various pathways, including pentose phosphate, mitochondrial tricarboxylic acid, de novo lipogenesis and gluconeogenesis [40]. In contrast, MAL and LA showed higher cytotoxicity profiles, with IC $_{50}$ values of 25.48 and $30.28 \mathrm{mM}$, respectively. Eutectic mixtures containing organic acids were reported to be toxic to cells, and the possible reason for the higher toxicity could be that the acidic condition is not suitable for cell growth, leading to cell death [44].

The antioxidant or free-radical-scavenging activities of NaDES have been poorly investigated, but in recent years, some studies reported on the antioxidant activities of NaDES using various antioxidant assays, such as oxygen radical activity (ORAC) [42,45] and ferric reducing antioxidant power (FRAP) [37]. The OPL flavonoids are well known to possess high free-radical-scavenging activity [18,19]. It is interesting to know whether the NaDES used to extract the flavonoids also show antioxidative properties since their precursors were primary metabolites, which were reported to show antioxidant capacities [45,46]. In this study, 2,2-diphenyl-1-picrylhydrazyl (DPPH) and nitric oxide (NO) freeradical-scavenging activities were investigated and the results are shown in Figure 5C,D, respectively. The results showed that amongst the six NaDES, LA showed the highest inhibition of DPPH and NO radicals (84 and 92\%, respectively). Kyle et al. reported lactic acid as having high antioxidant activity [47]. All the other NaDES exhibited moderate (31\% 
for BD) to weak (13-16\% for PD, GLY, GLU and MAL) inhibition of DPPH free radicals and $41-56 \%$ inhibition of NO free radicals. These results were also consistent with previous studies that reported that organic-acid-based $\mathrm{NaDES}$ are good free radical scavengers while at the same time showing a higher cytotoxicity profile compared to other alcohol- and sugar-based NaDES [40,45,48,49].
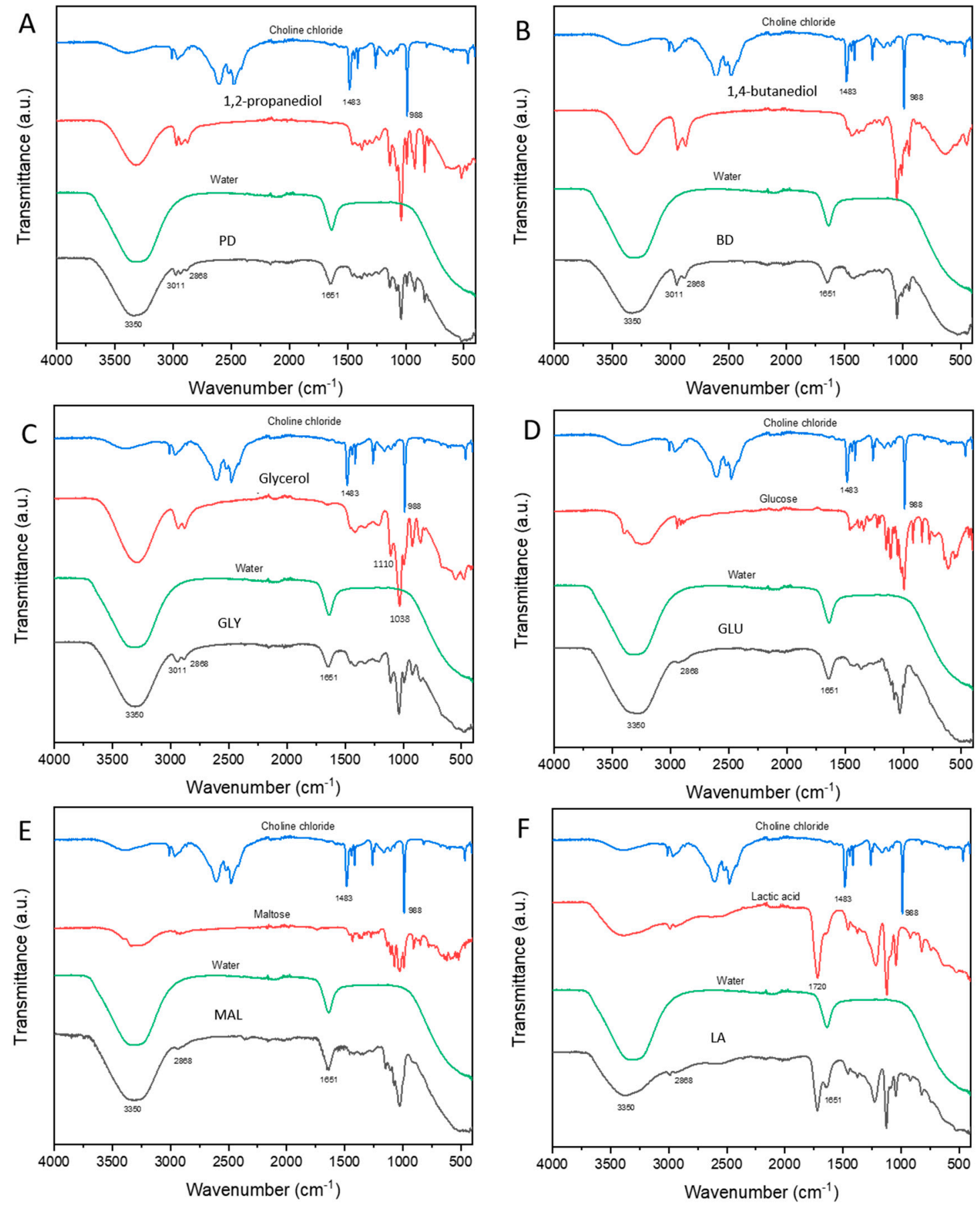

Figure 3. Fourier transform infrared (FT-IR) spectra of the NaDES along with their respective components: choline chloride:1,2-propanediol—PD (A), choline chloride:1,4-butanediol—BD (B), choline chloride:glycerol—GLY (C), choline chloride:glucose-GLU (D), choline chloride:maltose-MAL (E) and choline chloride:lactic acid—LA (F). 


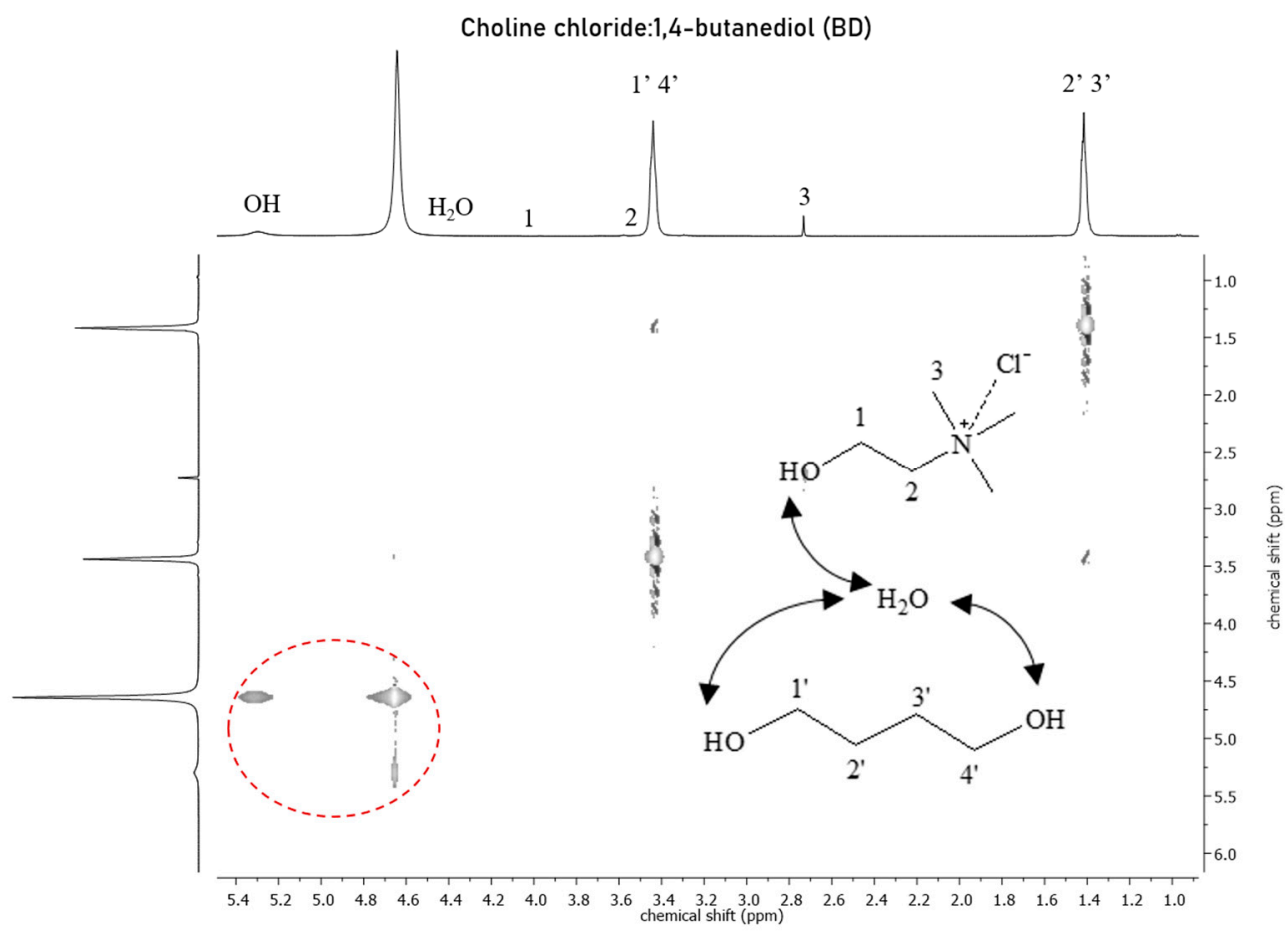

Figure 4. ${ }^{1} \mathrm{H}_{-}{ }^{1} \mathrm{H}$ nuclear overhauser enhancement spectroscopy (NOESY) spectra of BD—choline chloride:1,4-butanediol and $\mathrm{H}-\mathrm{H}$ interaction representation. The double-headed curved arrows indicate hydroxyl group interactions that were predicted to be present in the NaDES components. The red circle (dotted line) highlights the cross-peaks between the hydroxyl proton of either choline chloride or 1,4-butanediol with the water molecule in the system.

Lactic acid, or lactate, which is the form it commonly exists as, can be absorbed by cells via the monocarboxylate transporter (MCT) protein shuttle system. The acid generates cellular energy by converting to glucose via the Cori cycle, while lactate is oxidized to pyruvate to form carbon dioxide, water and NADH via lactate dehydrogenase $[47,50,51]$. The phenomenon of lactic acid overproduction is called lactic acidosis [52]. Under normal conditions, the cells are in a redox equilibrium state without experiencing a sudden spike of reactive oxygen species (ROS). The overexpression of LA as an antioxidant compound could cause a redox imbalance and lead to cell apoptosis. To look into different perspectives, the high radical-scavenging activity and low cell viability of organic acid-based $\mathrm{NaDES}$, i.e., LA, could be tailored to different purposes. For example, it can be used as a preservative, which demands extensive investigations. Many studies provided evidence of the destructive role of ROS in various human cancers, and excellent antioxidant free radical scavengers could potentially respond to this situation [53].

\subsection{Quantification of OPL Flavonoids in NaDES Extracts}

The performance of the six NaDES at extracting flavonoids was evaluated and compared to $\mathrm{MeOH}$. The OPL extracts after ultrasonic-assisted extraction using the individual $\mathrm{NaDES}$ and $\mathrm{MeOH}$ were analyzed to determine the total flavonoid (TFC), total luteolin (TLC), total apigenin (TAC), and total luteolin and apigenin contents (TLAC). Figure 6 shows that the alcohol-based NaDES (BD, PD and GLY) extracted the highest amount of flavonoids (16.34-20.36 mg QCE/g DP), which was comparable with the TFC that was obtained using MeOH (20.46 mg QCE/g DP). The sugar-based NaDES (GLU and MAL) extracted moderate amounts (12.67-13.92 mg/g QCE/g DP) while LA extracted the least amount with $9.92 \mathrm{mg} / \mathrm{g}$ QCE/g DP. The comparable efficiency of the more viscous NaDES with that of $\mathrm{MeOH}$ regarding extracting flavonoids from OPL powder was greatly assisted by the incorporation of ultrasonic waves. Ultrasonication could have caused a higher and more rapid mass transfer of flavonoids from the OPL powder into the more viscous NaDES, which generated similar results to those of the $\mathrm{MeOH}$. 

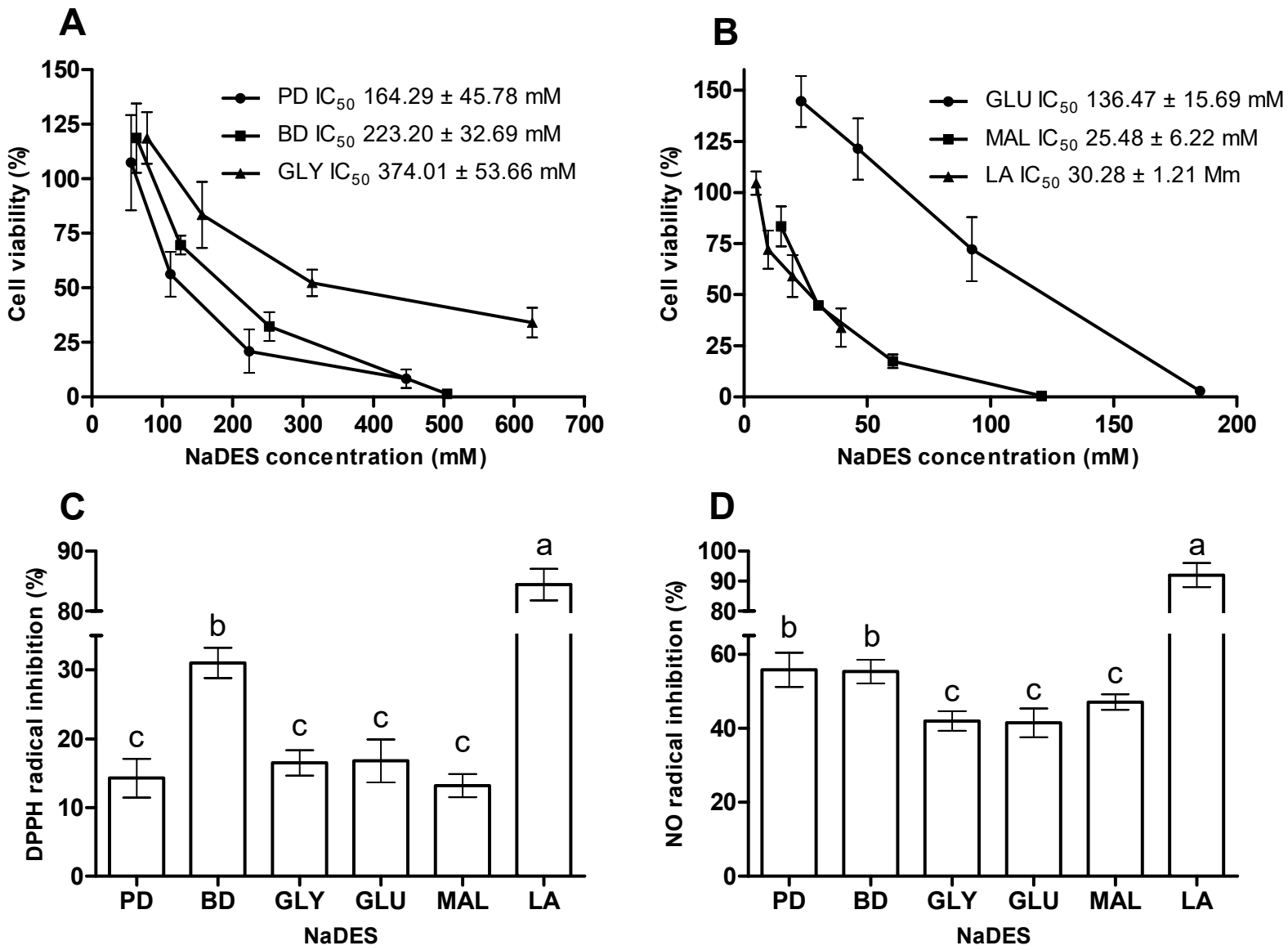

Figure 5. Results of the cytotoxicity and antioxidant assays on the synthesized NaDES. (A) Dose-response curves showing the viability of a $3 \mathrm{~T} 3$ fibroblast cell line that was exposed to PD, BD and GLY for $72 \mathrm{~h}$; (B) dose-response curves showing the viability of a 3 T3 fibroblast cell line that was exposed to GLU, MAL and LA for $72 \mathrm{~h}$. (C) Percentage inhibition of DPPH and (D) NO free radical. PD—choline chloride:1,2-propanediol, BD—choline chloride:1,4-butanediol, GLY—choline chloride:glycerol, GLU—choline chloride:glucose, MAL—choline chloride:maltose, LA—choline chloride:lactic acid. Values are presented as the mean \pm standard deviation of three measurements $(n=3)$. Bars with no common letters are significantly different $(p<0.05)$.

The relative quantification of the TLC and TAC were based on nine major peaks that were identified in our previously published works $[18,19,27]$. The UHPLC chromatograms of NaDES OPL extracts that were obtained in the present study were compared (Figure S5), and the peak numbers 1, 4, 5 and 7 were identified as luteolin-6,8-di-C-hexose, luteolin-6-C-hexose (isoorientin), luteolin-6-C-hexose (orientin) and luteolin-6-C-hexose-8$\mathrm{C}$-deoxyhexose, respectively. These luteolin derivatives were further quantified relative to orientin equivalents (mg OE/g DP) and summed to give the value for TLC. Meanwhile, the peak numbers $2,3,6,8$ and 9 were assigned to apigenin-6,8-di-C-hexose, apigenin6-C-pentose-8- $C$-hexose, apigenin-6-C-hexose (vitexin), apigenin-6-C-hexose (isovitexin) and apigenin-6-C-hexose-8-C-deoxyhexose, respectively. These apigenin derivatives were quantified relative to vitexin equivalents $(\mathrm{mg} \mathrm{VE} / \mathrm{g} \mathrm{DP})$ and summed to give the value for TAC. As shown in Figure 6B-D, the results indicated that the contents of the apigenin derivatives (117.61 to $135.69 \mathrm{mg} / \mathrm{g}$ TAC) were higher than those of luteolin derivatives (16.12-18.98 mg/g TLC).

The relative quantification results for TLC, which ranged from 16.12 to $18.98 \mathrm{mg} / \mathrm{g}$ with no significant difference between the individual NaDES, suggested that all six NaDES were efficient at extracting luteolin derivatives. These values were comparable to the TLC that was obtained using $\mathrm{MeOH}(17.28 \mathrm{mg} / \mathrm{g})$. The good efficiency of choline-chloridebased NaDES in extracting luteolin derivatives from plant matrices was also supported 
by other reports [10]. On the other hand, the relative quantification results for TAC revealed GLY to be superior at extracting apigenin derivatives. The TAC that was obtained using GLY (135.69 mg/g) was comparable to that obtained using MeOH. The remaining five NaDES were also moderately efficient at extracting apigenin derivatives, with TAC ranging from 117.61 to $128.18 \mathrm{mg} / \mathrm{g}$. These findings were consistent with previous reports on the suitability of alcohol-based NaDES in extracting apigenin derivatives from Cajanus cajan (L.) Millsp [5].

A Total Flavonoid Content

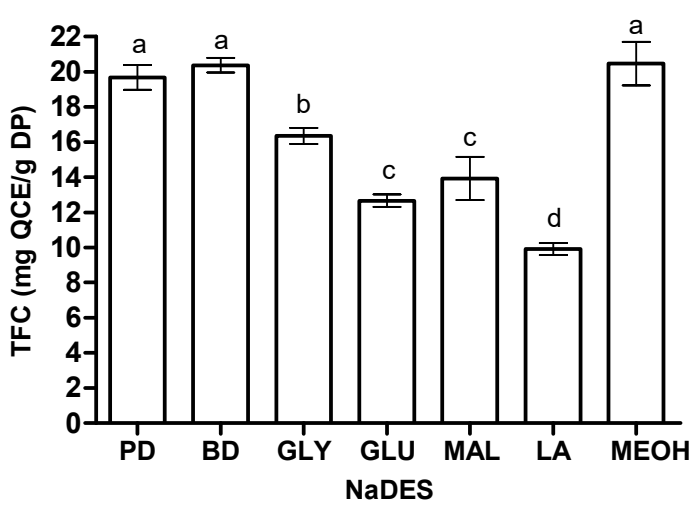

C Total Apigenin Content

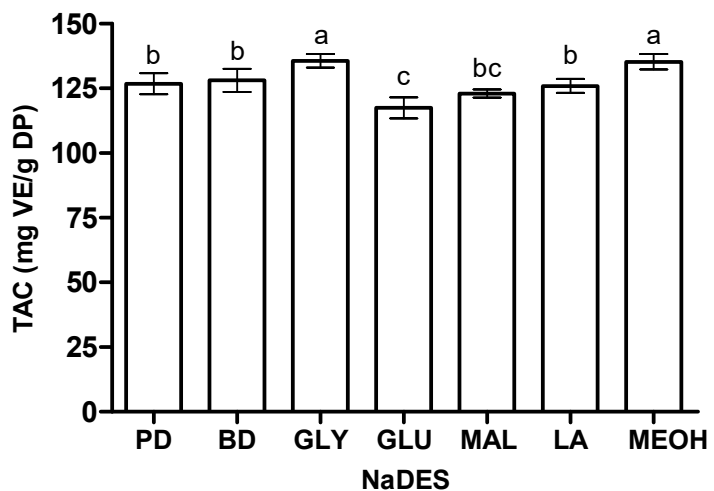

B Total Luteolin Content

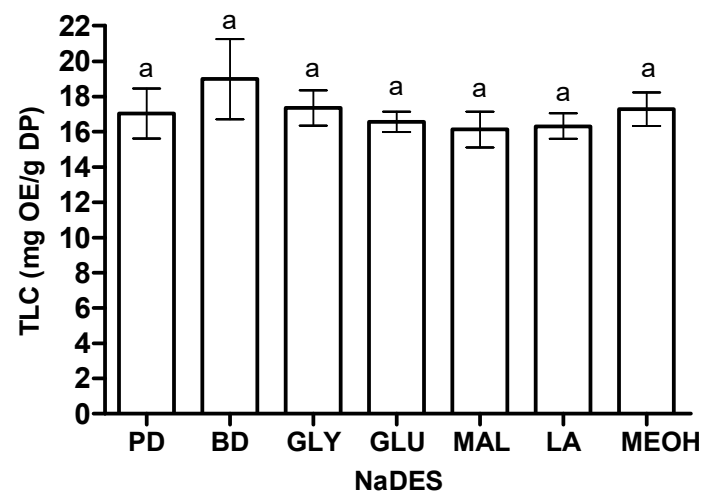

D Total Luteolin and Apigenin

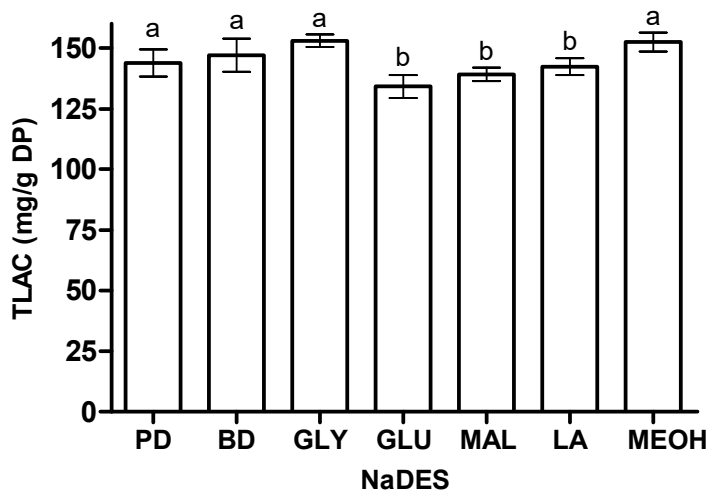

Figure 6. Determination of TFC — total flavonoid content (A), TLC—total luteolin content (B), TAC—total apigenin content (C) and TLAC — total luteolin and apigenin content (D) in OPL-NaDES extract solutions. MeOH-aqueous methanol was used as the reference solvent for the extraction of flavonoids from oil palm leaf. Values are presented as the mean \pm standard deviation of three measurements. Values marked with different letters indicate comparisons between NaDES that were statistically significant $(p<0.05)$ differences. PD—choline chloride:1,2-propanediol; BD—choline chloride:1,4-butanediol; GLY—choline chloride:glycerol; GLU—choline chloride:glucose; MAL—choline chloride:maltose; LA—choline chloride:lactic acid; QCE—quercetin equivalent; OE—orientin equivalent; VE—vitexin equivalent; DP—dried powder.

The TLAC that was obtained by the individual NaDES, which is the sum of the respective TLC and TAC, ranged from 134.17 to $153.04 \mathrm{mg} / \mathrm{g}$. The results revealed that GLY extracted the highest TLAC, followed by BD, PD, LA, MAL and GLU. With a TLAC of $153.04 \mathrm{mg} / \mathrm{g}$, GLY showed comparable ability with $\mathrm{MeOH}(152.63 \mathrm{mg} / \mathrm{g})$ at extracting luteolin and apigenin derivatives, which is a good indicator of its high potential for further practical application as an extraction solvent, particularly for OPL flavonoids. The hydroxyl and carbonyl groups that were present in the NaDES components initiated the hydrogen bonding interactions with the OPL flavonoid C-glycosides, which have moderate-to-high polarities. The results obtained in the present study are in accordance with the general preference of alcohols, organic acids and sugars as components in synthesizing NaDES for extracting phenolics and flavonoids from plant matrices $[10,27,54]$. 


\subsection{Relationship between Physicochemical Properties of NaDES and OPL Flavonoid Extraction}

The applicability of the synthesized NaDES in extracting OPL flavonoids, particularly luteolin and apigenin derivatives, could be driven by their physicochemical properties. Overall, the synthesized NaDES had higher density, polarity, water activity, viscosity and solvation capacity properties than the conventional organic solvent $\mathrm{MeOH}$. The matching polarity of the OPL flavonoids with that of the NaDES could explain the efficiency of the $\mathrm{NaDES}$ in extracting these compounds. The higher solvation capacity enhanced the binding ability of the NaDES with the targeted flavonoid in OPL during the extraction. Furthermore, the spectroscopic analysis revealed the presence of hydrogen bonding interactions in the NaDES due to the presence of several hydroxyl groups (-OH) in the NaDES components, including water. Similarly, the luteolin and apigenin derivatives, such as vitexin, isovitexin, orientin and isoorientin, have similar functional groups in their structures [55]. Hence, it is highly likely that the hydroxyl groups in the NaDES interacted with those in the OPL flavonoids, forming strong hydrogen bonds during the extraction. Being of higher viscosity than $\mathrm{COS}$, such as $\mathrm{MeOH}$, it is expected that efficient mass transfer is somewhat hindered during the extraction process. However, this drawback could be overcome by incorporating ultrasonic technology during the extraction process. In addition, the NaDES was found to be thermally stable at a set temperature, which did not cause solvent loss due to evaporation during extraction. The cytotoxicity profiles of the synthesized NaDES suggested that they were safe for use as extraction media.

\section{Conclusions}

Six NaDES were tailor-made using different combinations of choline chloride with 1,2-propanediol, 1,4-butanediol, glycerol, glucose, maltose and lactic acid. The synthesized NaDES not only showed strong hydrogen bonding interactions but also exhibited favorable physicochemical properties as extraction solvents. Furthermore, the synthesized NaDES were shown to have low cytotoxicity profiles, while the organic acid-based NaDES in particular, possessed additional free-radical-scavenging characteristics. An evaluation of their efficiencies at extracting OPL flavonoids revealed that among all the NaDES, the one prepared from the combination of choline chloride with glycerol (GLY) was the most efficient at extracting the target luteolin and apigenin derivatives, and was comparable to the efficiency of the conventional solvent, namely, methanol. The data that was generated in the present study has provided preliminary insights into the potential of NaDES as alternative green solvents for extracting OPL flavonoids. Understanding the relationship between the physicochemical properties of the NaDES and their extraction efficiencies has provided a stronger basis for the practical utilization of NaDES as environmentally friendly solvents for practical applications toward a more sustainable oil palm industry.

Supplementary Materials: The following are available online at https:/ / www.mdpi.com/article/10 .3390/su132312981/s1, Figure S1: Thermogravimetric analysis (TGA) thermograms of the NaDES, Figure S2: Differential scanning calorimetry (DSC) thermograms of the NaDES, Figure S3: Fourier transform infrared (FT-IR) spectra of methanol (A) and the NaDES (B). Figure S4: ${ }^{1} \mathrm{H}-{ }^{1} \mathrm{H}$ nuclear Overhauser enhancement spectroscopy (NOESY) spectra of the NaDES, including the $\mathrm{H}-\mathrm{H}$ interaction representation. Figure S5: Representative UV chromatograms of the OPL-NaDES extract solutions containing luteolin and apigenin derivatives at $340 \mathrm{~nm}$.

Author Contributions: K.S. and M.S.C.Z. conceptualized and designed the experiments; K.S. provided the research materials; M.S.C.Z. and J.X.Y. performed the experiments. M.S.C.Z. analyzed the data and wrote the manuscript; K.S. and S.Y.L. validated the data and edited the manuscript. All authors have read and agreed to the published version of the manuscript.

Funding: This research received no external funding.

Acknowledgments: The first author gratefully acknowledges Universiti Putra Malaysia for the award of Graduate Research Fellowship (GRF).

Conflicts of Interest: The authors declare no conflict of interest. 


\section{References}

1. Bentley, J.; Olsen, E.K.; Moore, J.P.; Farrant, J.M. The phenolic profile extracted from the desiccation-tolerant medicinal shrub Myrothamnus flabellifolia using natural deep eutectic solvents varies according to the solvation conditions. Phytochemistry 2020, 173, 112323. [CrossRef] [PubMed]

2. García, A.; Juan, E.M.R.; Gutiérrez, G.R.; Rios, J.J.; Fernández-Bolaños, J. Extraction of phenolic compounds from virgin olive oil by deep eutectic solvents (DESs). Food Chem. 2016, 197, 554-561. [CrossRef] [PubMed]

3. Santana, A.P.; Vargas, J.A.M.; Guimarães, T.G.; Amaral, C.; de Oliveira, A.P.; Gonzalez, M.H. Sustainable synthesis of natural deep eutectic solvents (NADES) by different methods. J. Mol. Liq. 2019, 293, 111452. [CrossRef]

4. Dai, Y.; Rozema, E.; Verpoorte, R.; Choi, Y.H. Application of natural deep eutectic solvents to the extraction of anthocyanins from Catharanthus roseus with high extractability and stability replacing conventional organic solvents. J. Chromatogr. A 2016, 1434, 50-56. [CrossRef]

5. Cui, Q.; Peng, X.; Yao, X.-H.; Wei, Z.-F.; Luo, M.; Wang, W.; Zhao, C.-J.; Fu, Y.-J.; Zu, Y.-G. Deep eutectic solvent-based microwave-assisted extraction of genistin, genistein and apigenin from pigeon pea roots. Sep. Purif. Technol. 2015, 150, 63-72. [CrossRef]

6. Huang, Y.; Feng, F.; Jiang, J.; Qiao, Y.; Wu, T.; Voglmeir, J.; Chen, Z.-G. Green and efficient extraction of rutin from tartary buckwheat hull by using natural deep eutectic solvents. Food Chem. 2017, 221, 1400-1405. [CrossRef] [PubMed]

7. Bi, W.; Tian, M.; Row, K.H. Evaluation of alcohol-based deep eutectic solvent in extraction and determination of flavonoids with response surface methodology optimization. J. Chromatogr. A 2013, 1285, 22-30. [CrossRef]

8. Nam, M.W.; Zhao, J.; Lee, M.S.; Jeong, J.H.; Lee, J. Enhanced extraction of bioactive natural products using tailor-made deep eutectic solvents: Application to flavonoid extraction from Flos sophorae. Green Chem. 2015, 17, 1718-1727. [CrossRef]

9. Wei, Z.-F.; Wang, X.-Q.; Peng, X.; Wang, W.; Zhao, C.-J.; Zu, Y.-G.; Fu, Y.-J. Fast and green extraction and separation of main bioactive flavonoids from Radix Scutellariae. Ind. Crop. Prod. 2015, 63, 175-181. [CrossRef]

10. Wei, Z.; Qi, X.; Li, T.; Luo, M.; Wang, W.; Zu, Y.; Fu, Y. Application of natural deep eutectic solvents for extraction and determination of phenolics in Cajanus cajan leaves by ultra performance liquid chromatography. Sep. Purif. Technol. 2015, 149, 237-244. [CrossRef]

11. Meng, Z.; Zhao, J.; Duan, H.; Guan, Y.; Zhao, L. Green and efficient extraction of four bioactive flavonoids from Pollen Typhae by ultrasound-assisted deep eutectic solvents extraction. J. Pharm. Biomed. Anal. 2018, 161, 246-253. [CrossRef]

12. Tomaševic, M.; Kovac, K.; Bubalo, M.C.; Natka, C. Green extraction of grape skin phenolics by using deep eutectic solvents. Food Chem. 2016, 200, 159-166.

13. Dai, Y.; Witkamp, G.-J.; Verpoorte, R.; Choi, Y.H. Natural deep eutectic solvents as a new extraction media for phenolic metabolites in Carthamus tinctorius L. Anal. Chem. 2013, 85, 6272-6278. [CrossRef] [PubMed]

14. Bajkacz, S.; Adamek, J. Development of a method based on natural deep eutectic solvents for extraction of flavonoids from food samples. Food Anal. Methods 2018, 11, 1330-1344. [CrossRef]

15. Mulia, K.; Muhammad, F.; Krisanti, E. Extraction of vitexin from binahong (Anredera cordifolia (Ten.) Steenis) leaves using betaine-1,4 butanediol natural deep eutectic solvent (NADES). AIP Conf. Proc. 2017, 1823, 1-4.

16. Liu, X.; Ahlgren, S.; Korthout, H.A.; Salomé-Abarca, L.F.; Bayona, L.M.; Verpoorte, R.; Choi, Y.H. Broad range chemical profiling of natural deep eutectic solvent extracts using a high performance thin layer chromatography-Based method. J. Chromatogr. A 2018, 1532, 198-207. [CrossRef] [PubMed]

17. Ofori-Boateng, C.; Lee, K.T. Sustainable utilization of oil palm wastes for bioactive phytochemicals for the benefit of the oil palm and nutraceutical industries. Phytochem. Rev. 2013, 12, 173-190. [CrossRef]

18. Che Zain, M.S.; Lee, S.Y.; Sarian, M.N.; Fakurazi, S.; Shaari, K. In vitro wound healing potential of flavonoid c-glycosides from oil palm (Elaeis guineensis Jacq.) leaves on 3t3 fibroblast cells. Antioxidants 2020, 9, 326. [CrossRef]

19. Che Zain, M.S.; Lee, S.Y.; Teo, C.Y.; Shaari, K. Adsorption and desorption properties of total flavonoids from oil palm (Elaeis guineensis Jacq.) mature leaf on macroporous adsorption resins. Molecules 2020, 25, 778. [CrossRef]

20. Tahir, N.I.; Shaari, K.; Abas, F.; Parveez, G.K.A.; Ishak, Z.; Ramli, U.S. Characterization of apigenin and luteolin derivatives from oil palm (Elaeis guineensis Jacq.) leaf using LC-ESI-MS/MS. J. Agric. Food Chem. 2012, 60, 11201-11210. [CrossRef] [PubMed]

21. Che Zain, M.S.; Edirisinghe, S.L.; Kim, C.-H.; De Zoysa, M.; Shaari, K. Nanoemulsion of flavonoid-enriched oil palm (Elaeis guineensis Jacq.) leaf extract enhances wound healing in zebrafish. Phytomedicine Plus 2021, 1, 100124. [CrossRef]

22. Rajoo, A.; Sasidharan, S.; Jothy, S.L.; Mansor, S.M. Ultrastructural study of Elaeis guineensis (oil palm) leaf and antimicrobial activity of its methanol extract against staphylococcus aureus. Top. J. Pharm. Res. 2013, 12, 419-423. [CrossRef]

23. Namvar, F. Antitumour Promoting Activity and Mode of Action of Methanolic Extracts of Selected Malaysian Seaweeds and Oil Palm Fronds. Ph.D. Thesis, Universiti Putra Malaysia, Seri Kembangan, Malaysia, 2009.

24. Sasidharan, S.; Logeswaran, S.; Latha, L.Y. Wound healing activity of Elaeis guineensis leaf extract ointment. Int. J. Mol. Sci. 2012, 13, 336-347. [CrossRef] [PubMed]

25. Dai, Y.; van Spronsen, J.; Witkamp, G.-J.; Verpoorte, R.; Choi, Y.H. Natural deep eutectic solvents as new potential media for green technology. Anal. Chim. Acta 2013, 766, 61-68. [CrossRef]

26. Che Zain, M.S.; Yeoh, J.X.; Lee, S.Y.; Afzan, A.; Shaari, K. Integration of choline chloride-based natural deep eutectic solvents and macroporous resin for green production of enriched oil palm flavonoids as natural wound healing agents. Antioxidants 2021, 10, 1802. [CrossRef] 
27. Dai, Y.; Witkamp, G.-J.; Verpoorte, R.; Choi, Y.H. Tailoring properties of natural deep eutectic solvents with water to facilitate their applications. Food Chem. 2015, 187, 14-19. [CrossRef] [PubMed]

28. Che Zain, M.S.; Osman, M.; Lee, S.; Shaari, K. UHPLC-UV/PDA method validation for simultaneous quantification of luteolin and apigenin derivatives from Elaeis guineensis leaf extracts: An Application for antioxidant herbal preparation. Molecules 2020, 26, 1084. [CrossRef] [PubMed]

29. Santana, A.P.; Andrade, D.F.; Vargas, J.A.M.; Amaral, C.; de Oliveira, A.P.; Gonzalez, M.H. Natural deep eutectic solvents for sample preparation prior to elemental analysis by plasma-based techniques. Talanta 2019, 199, 361-392. [CrossRef] [PubMed]

30. Dagnas, S.; Gougouli, M.; Onno, B.; Koutsoumanis, K.P.; Membré, J.-M. Quantifying the effect of water activity and storage temperature on single spore lag times of three moulds isolated from spoiled bakery products. Int. J. Food Microbiol. 2017, 240, 75-84. [CrossRef]

31. Savi, L.K.; Carpiné, D.; Waszczynskyj, N.; Ribani, R.H.; Haminiuk, C.W.I. Influence of temperature, water content and type of organic acid on the formation, stability and properties of functional natural deep eutectic solvents. Fluid Phase Equilibria 2019, 488, 40-47. [CrossRef]

32. Ruesgas-Ramón, M.; Figueroa-Espinoza, M.C.; Durand, E. Application of deep eutectic solvents (DES) for phenolic compounds extraction: Overview, challenges, and opportunities. J. Agric. Food Chem. 2017, 65, 3591-3601. [CrossRef] [PubMed]

33. Kua, Y.L.; Gan, S. Natural deep eutectic solvent (NADES) as a greener alternative for the extraction of hydrophilic (polar) and lipophilic (non-polar) phytonutrients. Key Eng. Mater. 2019, 797, 20-28. [CrossRef]

34. Liu, Y.; Friesen, J.B.; Mcalpine, J.B.; Lankin, D.C.; Chen, S.; Pauli, G.F. Natural deep eutectuc solvents: Properties, applications, and perspectives. J. Nat. Prod. 2018, 81, 679-690. [CrossRef] [PubMed]

35. Pigorsch, E. Spectroscopic characterisation of cationic quaternary ammonium starches. Starch/Staerke 2009, 61, 129-138. [CrossRef]

36. Mulia, K.; Krisanti, E.; Terahadi, F.; Putri, S. Selected natural deep eutectic solvents for the extraction of $\alpha$-mangostin from mangosteen (Garcinia mangostana L.) pericarp. Int. J. Technol. 2015, 6, 1211-1220. [CrossRef]

37. Jurić, T.; Uka, D.; Holló, B.B.; Jović, B.; Kordić, B.; Popović, B.M. Comprehensive physicochemical evaluation of choline chloride-based natural deep eutectic solvents. J. Mol. Liq. 2021, 343, 116968. [CrossRef]

38. Othman, Z.S.; Koketsu, M.; Karim, N.H.A.; Zubairi, S.I.; Hassan, N.H. Interaction study of binary solvent systems ionic liquid and deep eutectic solvent with rotenone. Sains Malays. 2018, 47, 1473-1482. [CrossRef]

39. Delso, I.; Lafuente, C.; Embid, J.M.; Artal, M. NMR study of choline chloride-based deep eutectic solvents. J. Mol. Liq. 2019, 290, 111236. [CrossRef]

40. Hayyan, M.; Mbous, Y.P.; Looi, C.Y.; Wong, W.F.; Hayyan, A.; Salleh, Z.; Mohd-Ali, O. Natural deep eutectic solvents: Cytotoxic profile. SpringerPlus 2016, 5, 1-12. [CrossRef] [PubMed]

41. Hayyan, M.; Looi, C.Y.; Hayyan, A.; Wong, W.F.; Hashim, M.A. In Vitro and in Vivo toxicity profiling of ammonium-based deep eutectic solvents. PLoS ONE 2015, 10, e0117934.

42. Radošević, K.; Ćurko, N.; Srček, V.G.; Bubalo, M.C.; Tomašević, M.; Ganić, K.K.; Redovniković, I.R. Natural deep eutectic solvents as beneficial extractants for enhancement of plant extracts bioactivity. LWT Food Sci. Technol. 2016, 73, 45-51. [CrossRef]

43. Hayyan, M.; Hashim, M.A.; AlSaadi, M.; Hayyan, A.; AlNashef, I.; Mirghani, M.E.S. Assessment of cytotoxicity and toxicity for phosphonium-based deep eutectic solvents. Chemosphere 2013, 93, 455-459. [CrossRef] [PubMed]

44. Zhao, B.-Y.; Xu, P.; Yang, F.-X.; Wu, H.; Zong, M.-H.; Lou, W.-Y. Biocompatible Deep eutectic solvents based on choline chloride: Characterization and application to the extraction of rutin from Sophora japonica. ACS Sustain. Chem. Eng. 2015, 3, $2746-2755$. [CrossRef]

45. Radošević, K.; Čanak, I.; Panić, M.; Markov, K.; Bubalo, M.C.; Frece, J.; Srček, V.G.; Redovnikovic, I.R. Antimicrobial, cytotoxic and antioxidative evaluation of natural deep eutectic solvents. Environ. Sci. Pollut. Res. 2018, 25, 14188-14196. [CrossRef] [PubMed]

46. Mitar, A.; Panić, M.; Radošević, K.; Redovnikovic, I.R.; Kučan, K.Z.; Sander, A.; Halambek, J.; Kardum, J.P. Physicochemical properties, cytotoxicity, and antioxidative activity of natural deep eutectic solvents containing organic acid. Chem. Biochem. Eng. Q 2019, 33, 1-18. [CrossRef]

47. Lampe, K.J.; Namba, R.M.; Silverman, T.R.; Bjugstad, K.; Mahoney, M.J. Impact of lactic acid on cell proliferation and free radical-induced cell death in monolayer cultures of neural precursor cells. Biotechnol. Bioeng. 2009, 103, 1214-1223. [CrossRef]

48. Ahmadi, R.; Hemmateenejad, B.; Safavi, A.; Shojaeifard, Z.; Mohabbati, M.; Firuzi, O. Assessment of cytotoxicity of choline chloride-based natural deep eutectic solvents against human HEK-293 cells: A QSAR analysis. Chemosphere 2018, 209, 831-838. [CrossRef] [PubMed]

49. Paiva, A.; Craveiro, R.; Aroso, I.; Martins, M.; Reis, R.L.; Duarte, A.R.C. Natural deep eutectic solvents-Solvents for the 21st century. ACS Sustain. Chem. Eng. 2014, 2, 1063-1071. [CrossRef]

50. Philp, A.; Macdonald, A.L.; Watt, P.W. Lactate-A signal coordinating cell and systemic function. J. Exp. Biol. 2005, 208, 4561-4575. [CrossRef]

51. Yanagida, S.; Luo, C.S.; Doyle, M.; Pohost, G.M.; Pike, M.M. Nuclear magnetic resonance studies of cationic and energetic alterations with oxidant stress in the perfused heart: Modulation with pyruvate and lactate. Circ. Res. 1995, 77, 773-783. [CrossRef]

52. Kraut, J.A.; Madias, N.E. Lactic acidosis. N. Engl. J. Med. 2014, 371, 2309-2319. [CrossRef] [PubMed] 
53. Sammar, M.; Abu-Farich, B.; Rayan, I.; Falah, M.; Rayan, A. Correlation between cytotoxicity in cancer cells and free radicalscavenging activity: In vitro evaluation of 57 medicinal and edible plant extracts. Oncol. Lett. 2019, 18, 6563-6571. [CrossRef] [PubMed]

54. Koutsoukos, S.; Tsiaka, T.; Tzani, A.; Zoumpoulakis, P.; Detsi, A. Choline chloride and tartaric acid, a natural deep eutectic solvent for the efficient extraction of phenolic and carotenoid compounds. J. Clean. Prod. 2019, 241, 118384. [CrossRef]

55. Che Zain, M.S.; Lee, S.Y.; Teo, C.Y.; Shaari, K. Adsorption/desorption characteristics and simultaneous enrichment of orientin isoorientin, vitexin and isovitexin from hydrolyzed oil palm leaf extract using macroporous resins. Processes 2021, 9, 659. [CrossRef] 